\title{
Die rol van die kerk as ondersteuningsnetwerk - Die verwantskap tussen psigo-sosiale klimaat, kerklike betrokkenheid en sielkundige welsyn
}

\author{
T.B. Pretorius \\ Departement Sielkunde, Universiteit van Wes-Kaapland, Privaatsak X17, Bellville 7507, Republiek van Suid-Afrika \\ D.J. Malan* \\ Departement Psigologie, Vaaldriehoekkampus, PU VIR CHO, Vanderbijlpark 1900, Republiek van Suid-Afrika
}

\author{
P.M. Heyns
}

Departement Sielkunde, Universiteit van Wes-Kaapland, Bellville, Republiek van Suid-Afrika

Ontvang Oktober 1989; aanvaar Desember 1989

\begin{abstract}
The role of the church as a supportive network: The relationship between psycho-social climate, church involvement and psychological well-being. The aim of the present study was to determine whether mere involvement in church activities is enough to perceive the church as supportive, or whether the church should possess certain qualities before it is experienced as being supportive. The concept of psycho-social climate was used as a conceptual frame of reference to study the characteristics of the church. Two hundred and fourteen members of 10 different congregations completed a battery of questionnaires designed to measure their involvement in the church, their perception of the psycho-social climate of the church and their level of psychological well-being. No relationship between church involvement and psychological well-being could be found. On the other hand the analysis of the relationship between the dimensions of church climate and psychological well-being produced a number of significant correlations. Step-wise multiple regression analysis confirmed that the psycho-social dimensions of order/ciarity, social concern, stability and activity were significant predictors of level of psychological well-being. The obtained relationship was interpreted as confirmation of the impact that the psycho-social environment has on individual functioning.
\end{abstract}

Die oogmerk van die onderhawige studie was om vas te stel of blote kerklike bywoning en betrokkenheid as sodanig voldoende is vir die ervaring van die kerk as 'n ondersteuningsnetwerk, en of die kerk vir dié doel ook oor bepaalde waarneembare kwaliteite moet beskik. Die konsep van kerklike psigo-sosiale klimaat is ingespan as 'n konseptuele verwysingsraamwerk vir die ondersoek van die kwaliteite van die kerk. Die proefpersone, 214 lidmate van 10 kerklike gemeentes, het 'n battery van vraelyste wat hulle mate van betrokkenheid by die kerk, hulle persepsie van die psigo-sosiale klimaat binne die kerk en hulle vlak van sielkundige welsyn gemeet het, voltooi. Geen verband tussen lidmate se kerklike betrokkenheid en hulle vlak van sielkundige welsyn kon gevind word nie, terwyl die vergelyking tussen die dimensies van psigo-sosiale klimaat en die dimensies van sielkundige welsyn ' $n$ aantal betekenisvolle korrelasies opgelewer het. ' $n$ Stapsgewyse meervoudige regressie-ontleding het ook bevestig dat sekere dimensies van psigo-sosiale klimaat, te wete normatiewe ondubbelsinnigheid, sosiale besorgdheid, stabiliteit en aktiwiteit, betekenisvolle voorspellers van sielkundige welsyn is. Die verkreë korrelasies is beskou as bevestiging van die impak wat die psigo-sosiale omgewing op individuele funksionering het.

*Aan wie korrespondensie gerig moet word

Sielkundiges besef in 'n toenemende mate dat die trefwydte van die toegepaste sielkunde verbreed moet word om nie alleen die individu nie, maar ook die verhouding tussen die individu en sy sosiale omgewing in te sluit. Ten spyte van hierdie besef het die godsdienstige bestel, as faset van die sosiale omgewing, in die verlede selde die aandag van sielkundiges geniet. Rappaport (1981) is die mening toegedaan dat godsdienstige instellings of heeltemal deur geestesgesondheidsdienste geïgnoreer word, of as tweederangse geestesgesondheidsagentskappe beskou word, wat nie werklik 'n rol te vervul het ten opsigte van die bevordering van geestesgesondheid nie.

Sommige outeurs voel egter dat, vanweë die sentrale rol wat die godsdiens en godsdienstige instansies in die lewe van die mens speel, nouer kontak tussen die kerk en gemeenskapsgeestesgesondheidsdienste aangemoedig behoort te word (Allport, 1968; Haugk, 1976; Pargament, 1982). In dié verband word ook gepraat van die ongerealiseerde potensiaal wat die kerk ten opsigte van gemeenskapsgeestesgesondheid het (Bufford \& Johnson, 1982).

Dit is veral ten opsigte van primêre voorkoming dat die kerk in 'n unieke posisie is om 'n bydrae te lewer. Primêre voorkoming word breedweg omskryf as die bevordering van gunstige toestande in die omgewing om sodoende die vermindering van die voorkoms en selfs uitskakeling van psigo-sosiale versteurings in 'n bevolking te bewerkstellig (Caplan, 1963; Cowen, 1977). Dit word allerweë aanvaar dat ondersteuningsnetwerke 'n belangrike rol te speel het in primêre voorkoming, veral met betrekking tot die bevordering van die individu se vermoë om lewensprobleme effektief te hanteer (Caplan, 1964; Maton \& Rappaport, 1984; Myers, Lindenthal \& Pepper, 1975; Rabkin \& Struening, 1976; Reif, 1968).

Vanweë die potensiaal van dic kerk om 'n gemeenskap, wat gekenmerk word deur liefde, aanvaarding, 
warmte en sosiale ondersteuning daar te stel (Haugk, 1976), is die kerk in 'n unieke posisie om as ondersteuningsnetwerk te fungeer. Die skep van ondersteuningsgroepe binne die kerk kan persone ook op gebeurtenisse soos die huwelik, ouerskap, aftrede en die dood voorberei. Caplan (1964) verwys hierna as emosionele inenting.

Die kerk se besondere rol as ondersteuningsisteem is veral te danke aan die toeganklikheid daarvan vir persone in nood en die feit dat dit ook as toevlugsoord en akkommodeerder van persone met 'n minderheidstatus soos byvoorbeeld bejaardes en etniese minderheidsgroepe dien.

Die miskenning van die rol van godsdienstige instansies moet waarskynlik toegeskryf word aan 'n blote aanvaarding van die ondersteuningsfunksie van die kerk. Baie min studies het reeds aandag geskenk aan die vraag of blote deelname aan kerklike aktiwiteite voldoende vir lidmate is om ondersteuning te ervaar, en of die kerk nie ook oor bepaalde kenmerke moet beskik of dimensies moet openbaar alvorens die kerk sy ondersteuningsfunksie realiseer nie.

Baanbrekerswerk ten opsigte van kenmerke van die kerk is veral deur Kenneth Pargament en sy medewerkers gedoen (Pargament, Silverman, Johnson, Echemendia \& Snyder, 1983) met die konseptualisering van die kerklike psigo-sosiale klimaat. Op grond van die teoretiese en empiriese literatuur oor psigo-sosiale klimaat het die outeurs kerklike klimaat as sielkundig betekenisvolle kognitiewe voorstellings van die kerk gedefinieer. Kerklike klimaat word gesien as 'n tussenkomende veranderlike wat die invloed van die kerk op die individuele lid bemiddel. Dit is dan veral hierdie bemiddelingsfunksie van kerklike klimaat wat suggereer dat die kerk nie op sigself as ondersteuningsnetwerk fungeer nie, maar dat lidmate bepaalde klimaatsfaktore binne die kerk moet waarneem, alvorens die kerk as ondersteunend ervaar gaan word.

Een indeks van die effek van ondersteuningsnetwerke is die vlak van sielkundige welsyn. Turner (1981) het byvoorbeeld bevind dat daar 'n positiewe verband tussen ondersteuningsnetwerke en sielkundige welsyn bestaan. Indien die kerk dus wel as ondersteuningsnetwerk fungeer, behoort dit 'n positiewe uitwerking op lidmate se vlak van sielkundige welsyn te demonstreer.

Die doel van hierdie navorsing was om vas te stel of kerklike betrokkenheid op sigself verband hou met sielkundige welsyn as indeks van die effek van ondersteuningsnetwerke, en of sielkundige welsyn slegs beïnvloed word deur die persepsie van gunstige kerklike klimaatsfaktore binne die kerk.

Die studie word dan ook gelei deur die vraag of kerklike betrokkenheid, of kerklike psigo-sosiale klimaat die beste voorspeller van sielkundige welsyn is.

\section{Metode}

Meetmiddels

Kerklike betrokkenheidsvraelys (KBV)

Die mate van lidmaatbetrokkenheid by die kerk is gemeet deur vyf items: frekwensie van kerkbywoning, frekwensie van deelname aan sosiale aktiwiteite van die kerk, antal ure wat aan kerklike aktiwiteite bestee word, aantal kerklike aktiwiteite waarby die lidmaat betrokke is en aantal gemeentelede wat die lidmaat by die naam ken. Response op hierdie vraelys word gelewer in terme van 'n sespuntskaal.

\section{Kerklike klimaatskaal (KKS)}

Die KKS is deur Pargament en sy medewerkers (1983) opgestel en bestaan uit 64 stellings wat agt verskillende dimensies van kerklike klimaat meet. Die agt dimensies is die gemeenskapsgevoel wat deur die kerk gebied word, die vlak van ekspressiwiteit wat in die kerk aangemoedig word, die mate van normatiewe ondubbelsinnigheid wat in die kerk se aktiwiteite bestaan, die mate van sosiale besorgdheid wat in die kerk waargeneem word, die kerk se openheid vir verandering ten opsigte van die idees en aktiwiteite van lidmate, die mate waartoe die kerk outonomie ten opsigte van lidmate se oortuigings en gedrag aanmoedig, die vlak van stabiliteit in die gemeente se organisasie en laastens die kerk se vlak van aktiwiteit. Voldoende bewyse van geldigheid en betroubaarheid (Alfa-koëffisiënte wat strek vanaf 0,70 tot 0,83 ) word deur die outeurs verskaf. Vir die doeleindes van hierdie studie is die vraelys aangepas en vertaal. Die items van die vraelys is so opgestel dat die proefpersone se response in terme van 'n vyfpunt-skaal gelewer word.

\section{'Hoe ek voel'-vraelys (HEV)}

Die HEV is 'n verkorte weergawe van 'n vraelys wat oorspronklik deur Petersen en Kellam (1977) ontwikkel is en wat daarop gemik was om sielkundige welsyn te meet deur te fokus op drie dimensies, te wete angs, depressie en aggressie. Die outeurs het dan ook aangedui dat die HEV betroubaar (Alfa-koëffisiënte wat strek vanaf 0,74 tot 0,76 ) en geldig genoeg is. Alhoewel die HEV aanvanklik ontwikkel is vir gebruik met adolessente het Turner (1981) aangedui dat dit met vrug toegepas kan word op volwassenes, aangesien hy bevredigende betroubaarheidskoëffisiënte vir drie verskillende steekproewe gevind het (Alfa-koëffisiënte wat strek vanaf 0,72 tot 0,83 ). Die HEV is ook gestandaardiseer op 'n Amerikaanse steekproef, maar aangesien dit in die onderhawige studie slegs gaan oor 'n indeks van sielkundige welsyn was dit nie nodig om van hierdie norme gebruik te maak nie. Vir die doeleindes van die huidige studie is die HEV ook in Afrikaans vertaal. Die response op die HEV is op so 'n wyse gekodeer dat hoë tellings op die skaal aanduidend is van swak sielkundige aanpassing, terwyl lae tellings aanduidend is van goeie sielkundige aanpassing.

\section{Proefpersone}

Respondente het uit 214 kerklidmate bestaan wat afkomstig was van 10 gemeentes versprei oor die woongebiede van Bellville-Suid, Kuilsrivier, en Belhar in die Kaapse Skiereiland. Die 214 vraelyste verteenwoordig 
Tabel 1 Opsomming van die psigometriese eienskappe van die verskillende vraelyste

\begin{tabular}{lcccc}
\hline Vraelys & $\begin{array}{c}\text { Aantal } \\
\text { Items }\end{array}$ & $\begin{array}{c}\text { Skaal } \\
\text { gemiddelde }\end{array}$ & $\begin{array}{c}\text { Standaard } \\
\text { Afwyking }\end{array}$ & $\begin{array}{c}\text { Alfa } \\
\text { koëffisiënte }\end{array}$ \\
\hline KBV & 4 & 12,94 & 4,17 & 0,80 \\
KKS: & & & & \\
Ekspressiwiteit & 5 & 14,87 & 4,22 & 0,56 \\
Normatiewe ondubbelsinnigheid & 7 & 26,28 & 5,44 & 0,75 \\
Gemeenskapsgevoel & 8 & 27,31 & 6,05 & 0,75 \\
Sosiale besorgdheid & 7 & 21,11 & 7,11 & 0,86 \\
Openheid vir verandering & 6 & 18,90 & 4,89 & 0,72 \\
Outonomie & 6 & 18,95 & 5,41 & 0,79 \\
Stabiliteit & 7 & 29,62 & 6,45 & 0,73 \\
Aktiwiteit & 6 & 19,15 & 5,07 & 0,74 \\
HEV: & & & & \\
Angs & 7 & 16,30 & 5,61 & 0,84 \\
Aggressie & 6 & 13,30 & 5,02 & 0,87 \\
Depressic & 6 & 11,01 & 5,14 & 0,86 \\
\hline
\end{tabular}

KBV - Kerklike betrokkenheidsvraelys

KKS - Kerklike klimaatskaal

HEV - Hoe ek voel vraelys

Tabel 2 Produkmoment-korrelasies tussen kerklike betrokkenheid en sielkundige welsyn $(N=214)$

\begin{tabular}{lcc}
\hline Dimensies & $\mathrm{r}$ met betrokkenheid & betekenisvolheid \\
\hline Angs & $-0,028$ & $p>0,05$ \\
Aggressie & $-0,038$ & $p>0,05$ \\
Depressie & $-0,069$ & $p>0,05$ \\
\hline
\end{tabular}

Tabel 3 Produkmoment-korrelasies tussen sielkundige welsyn en dimensies van kerklike klimaat

\begin{tabular}{lccc}
\hline & \multicolumn{2}{c}{ Dimensies van sielkundige welsyn } \\
\cline { 2 - 4 } & Angs & Aggressie & Depressie \\
\hline Dimensies van kerklike klimaat & & & \\
Normatiewe ondubbelsinnigheid & $-0,245^{* *}$ & $-0,131$ & $-0,235^{* *}$ \\
Gemeenskapsgevoel & $-0,137^{*}$ & $-0,037$ & $-0,120$ \\
Sosiale besorgdheid & $-0,032$ & 0,037 & $-0,017$ \\
Openheid vir verandering & $-0,146^{*}$ & $-0,139^{*}$ & $-0,079$ \\
Outonomie & $-0,162^{*}$ & $-0,039$ & $-0,104$ \\
Stabiliteit & $-0,170^{*}$ & $-0,157^{*}$ & $-0,150^{* *}$ \\
Aktiwiteit & 0,050 & 0,083 & $0,168^{*}$ \\
\hline
\end{tabular}

$* p=0,05$

${ }^{* *} p=0,01$

'n responskoers van $33 \%$. 'n Opsomming van die vernaamste kenmerke van die respondente dui aan dat:

(a) $45 \%$ van die respondente vroulik en $55 \%$ manlik was

(b) die gemiddelde ouderdom van die respondente 35 jaar was en die oorgrote meerderheid van die respondente in die ouderdomsgroep 30 tot 50 jaar geval het (c) $59 \%$ van die respondente getroud was, $36 \%$ ongetroud, $3 \%$ geskei en $2 \%$ hulle wederhelf aan die dood afgestaan het

(d) $28 \%$ van die respondente Engelssprekend was, terwyl $72 \%$ Afrikaanssprekend was

(e) die onderskeie kerke wat in die onderhawige studie gebruik was, soos volg versprei was: Congregational kerk (Bellville en Kuilsrivier gemeentes), Lutherse kerk (Bellville gemeente), Morawiese kerk (Bellville gemeente), Nederduits Gereformeerde Sendingkerk (Belhar gemeente), Calvynse kerk (Kuilsrivier gemeente).

\section{Resultate}

Die drie meetinstrumente was eers aan betroubaarheidsontledings onderwerp. Tabel 1 verskaf 'n opsomming van die psigometriese eienskappe van die vraelyste.

Uit Tabel 1 blyk dit dat die betroubaarheidskoëffisiënte van die onderskeie vraelyste, met die uitsondering van die ekspressiwiteitsdimensie van die KKS heeltemal aanvaarbaar is. Gevolglik is besluit om die ekspressiwiteitsdimensie heeltemal buite berekening te laat in verdere ontledings.

Die eerste stap was om die verband tussen kerklike betrokkenheid en sielkundige welsyn deur middel van produkmoment-korrelasies te ondersoek. Die resultate van hierdie ontleding verskyn in Tabel 2.

Uit Tabel 2 blyk dit dat al die verkreë koëffisiënte te laag is om enigsins betekenisvol te wees, met die implikasie dat geen verband tussen kerklike betrokkenheid en sielkundige welsyn gedemonstreer kan word nie.

Tweedens is gepoog om vas te stel of daar 'n verband tussen kerklike psigo-sosiale klimaat en sielkundige welsyn bestaan. Die interkorrelasies tussen die dimensies van kerklike klimaat en sielkundige welsyn word aangetoon in Tabel 3. 
Tabel 4 Betekenisvolle regressiekoëffisiënte $(\alpha=0,05)$ in die voorspelling van sielkundige welsyn

\begin{tabular}{|c|c|c|c|c|}
\hline Onafhanklike veranderlikes & $\begin{array}{c}\text { Beta- } \\
\text { koëffisiënte }\end{array}$ & $F$-Waarde & $R$ & $R^{2}$ \\
\hline \multicolumn{5}{|l|}{ Voorspelling van angs } \\
\hline Normatiewe ondubbelsinnigheid & $-0,223$ & 8,684 & 0,223 & 0,05 \\
\hline Sosiale besorgdheid & 0,155 & 3,417 & 0,263 & 0,07 \\
\hline \multicolumn{5}{|l|}{ Voorspelling van aggressie } \\
\hline Stabiliteit & $-0,170$ & 4,946 & 0,171 & 0,03 \\
\hline \multicolumn{5}{|l|}{ Voorspelling van depressie } \\
\hline Aktiwiteit & 0,221 & 8,506 & 0,221 & 0,05 \\
\hline Normatiewe ondubbelsinnigheid & $-0,225$ & 9,059 & 0,314 & 0,10 \\
\hline
\end{tabular}

Uit Tabel 3 blyk dit dat angs betekenisvol negatief korreleer met normatiewe ondubbelsinnigheid, gemeenskapsgevoel, openheid vir verandering, outonomie en stabiliteit. Daar is ook 'n negatiewe verband tussen aggressie en openheid vir verandering en stabiliteit. Depressie toon ' $n$ betekenisvolle positiewe verband met aktiwiteit en 'n negatiewe verband met stabiliteit en normatiewe ondubbelsinnigheid.

Ten einde vas te stel watter veranderlikes die beste voorspellers van sielkundige welsyn is, is stapsgewyse meervoudige regressie-ontledings uitgevoer met elk van die dimensies van sielkundige welsyn as die afhanklike veranderlike. Die resultate van hierdie ontledings verskyn in Tabel 4.

Tabel 4 toon dat die stapsgewyse meervoudige regressie-ontleding in die geval van angs en depressie na die tweede stap gestaak is, terwyl dit in die geval van aggressie na die eerste stap gestaak is. Dit beteken dat slegs normatiewe ondubbelsinnigheid en sosiale besorgdheid betekenisvolheid as voorspellers van angs bereik het. Hierdie twee dimensies van kerklike psigososiale klimaat verklaar gesamentlik $7 \%$ van die variansie in angs. Slegs stabiliteit het betekenisvolheid bereik as voorspeller van aggressie en hierdie dimensie van kerklike psigo-sosiale klimaat verklaar $3 \%$ van die variansie in aggressie. Aktiwiteit en normatiewe ondubbelsinnigheid is die enigste betekenisvolle voorspellers van depressie en gesamentlik verklaar hierdie twee dimensies $10 \%$ van die variansie in depressie.

\section{Bespreking}

Die resultate toon dat daar nie 'n direkte verband tussen kerklike betrokkenheid en sielkundige welsyn bestaan nie, maar dat sielkundige welsyn wel in verband met bepaalde dimensies van die kerk se psigo-sosiale klimaat staan. Meervoudige regressie-ontledings toon dat die volgende dimensies van kerklike psigo-sosiale klimaat betekenisvolle voorspellers van die onderskeie dimensies van sielkundige welsyn is: normatiewe ondubbelsinnigheid, sosiale besorgdheid, stabiliteit en aktiwiteit. Weens die korrelasionele aard van die studie, wat dit moeilik maak om uitsluitsel te gee oor die rigting van oorsaaklikheid, behoort die volgende verklarings slegs gesien te word as moontlike interpretasies van die verkreë korrelasies. Hierdie verklarings voorveronderstel sielkundige welsyn as afhanklike veranderlike. Uiteraard kan verwag word dat die korrelasie tussen sielkundige welsyn en klimaatsdimensies nie hoog kan wees nie, aangesien die vlak van sielkundige welsyn deur 'n verskeidenheid van faktore bepaal word.

Die bevinding dat normatiewe ondubbelsinnigheid negatief met angs en depressie korreleer beteken dat persone wat 'n hoë mate van duidelikheid in die reëls en aktiwiteite van die kerk waarneem, ook 'n lae mate van angs en depressie ervaar (Hoë tellings op die PEV is aanduidend van 'n lae vlak van sielkundige welsyn). Hierdie bevinding sou in 'n sekere mate aansluiting kon vind by die anomie-literatuur wat aantoon dat 'n lae mate van struktuur of normloosheid 'n nadelige uitwerking op 'n individu se sielkundige funksionering (Robinson \& Shaver, 1976) het.

Die bevinding dat gemeenskapsgevoel negatief met angs korreleer, beteken dat persone wat 'n sin van ondersteuning, broederskap en 'n sin van affiliasie ervaar, ook minder angs ervaar. Dit is dan veral hierdie bevinding wat die rasionaal agter ondersteuningsnetwerke bevestig, dit is dat warme, intieme menslike verhoudings gesien word as ' $n$ bron van ondersteuning.

Die bevinding dat openheid vir verandering negatief korreleer met angs en aggressie, beteken dat diegene wat die kerk sien as baie ontvanklik vir veranderinge in programme en reëls, ook minder angs en aggressie ervaar.

Persone wat 'n hoë mate van outonomie in die kerk waarneem, dit wil sê, wat glo dat die kerk individualiteit onder sy lede aanmoedig, ervaar ook minder angs. Diegene wat 'n hoë mate van stabiliteit in die kerk waarneem, ervaar minder angs, depressie en aggressie terwyl diegene wat 'n hoë vlak van aktiwiteit binne die kerk waarneem, meer depressiwiteit ervaar. Dit kan wees dat sulke persone waarskynlik uitgesluit voel uit hierdie aktiwiteite en gevolglik meer depressiwiteit ervaar. Andersins kan dit egter ook wees dat die hoë vlak van aktiwiteit in die kerk te ongestruktureerd is.

Hierdie interkorrelasies bevestig weer eens die potensiaal van die kerk ten opsigte van die bevordering 
van positiewe geestesgesondheid, daar dit eienskappe en kwaliteite uitlig wat direk in verband staan met sielkundige welsyn. Voorts dui dit daarop dat die konsep van kerklike psigo-sosiale klimaat 'n belangrike rol te speel het in die konseptuele beskrywing van godsdienstige instansies. Sodanige beskrywing van sosiale omgewings waarin die mens leef en funksioneer, word dan ook gesien as voorvereiste vir ingryping en wysiging van sosiale omgewings (Murrel, 1973; Pargament, Tyler \& Steele, 1979). Indien sielkundige welsyn as afhanklike veranderlike veronderstel word, kan die voorafgaande bevindinge vertolk word as bevestiging van die effek van die psigo-sosiale omgewing op menslike funksionering. Dit is duidelik dat aspekte soos ondubbelsinnigheid, gemeenskapsgevoel, openheid vir verandering, outonomie en stabiliteit nie slegs aspekte is wat tuishoort binne die kerk nie, maar in enige omgewing van belang is. In hierdie verband het Moos (1987) byvoorbeeld aangedui dat verhoudingsdimensies (gemeenskapsgevoel), persoonlike ontwikkelingsdimensies (outonomie) en sisteeminstandhoudings- en sisteemsveranderingsdimensies (ondubbelsinnigheid, openheid vir verandering en stabiliteit) kenmerkend is van 'n verskeidenheid van omgewings, ondermeer werksomgewings, opvoedkundige omgewings en behandelingsomgewings. Uit die studie blyk voorts dat die kerk as geïnstitusionaliseerde godsdiens moontlik die potensiaal het om persone se geestesgesondheid te beïnvloed, en hierdie potensiaal behoort deur sielkundiges benut te word. Dit vereis egter dat daardie dimensies van kerklike klimaat wat in die huidige studie uitgelig is optimaal benut word. Hiervoor is uiteraard 'n nouer samewerking tussen sielkundiges, kerkleiers an ander verwante dissiplines nodig.

\section{Summary}

In this article the role of the church as a support system is examined. More specifically, it was attempted to determine whether mere involvement in church activities is enough to perceive the church as supportive, or whether members should perceive certain qualities in the church before the church is seen as supportive. The concept of psycho-social climate was used as a frame of reference to study the characteristics of the church. Two hundred and fourteen members of 10 different congregations completed a battery of questionnaires designed to measure their involvement in the church, their perception of the psycho-social climate of the church and their level of psychological well-being. All the questionnaires were translated and adapted to the South African context and their psychometric properties reassessed. All of the questionnaires proved to be relatively reliable for this sample.

As was expected no relationship between church involvement and psychological well-being could be found. On the other hand the analysis of the relationship between the dimensions of church climate and psychological well-being produced a number of significant correlations. The measure of order/clarity in the activities of the church was related to the level of anxiety and de- pression experienced by the members. The sense of community offered by the church was related to members' level of anxicty. The congregation's openness to change in ideas and activities was related to members' level of aggression and anxiety. The extent to which the church supports member autonomy in beliefs and behaviour was related to members' level of anxiety. The stability of the church as an organization was related to members' level of anxiety, depression and aggression. The church's level of activity was related to the members' level of depression. These relationships serve as an indication of the potential the church has as a support system. These results were further interpreted as confirmation of the impact the environment has on individual functioning.

\section{Verwysings}

Allport, G.W. (1968). The person in psychology: Selected essays. Boston: Beacon Press.

Bufford, R.K. \& Johnston, T.B. (1982). The church and community mental health: Unrealized potential. Journal of Psychology and Theology, 10, 355-362.

Caplan, G. (1963). Types of mental health consultation. American Journal of Orthopsychiatry, 33, 470-481.

Caplan, G. (1964). Principles of preventive psychiatry. New York: Basic Books.

Cowen, E.L. (1977). Baby steps toward primary prevention. American Journal of Community Psychology, 5(1), 1-22.

Haugk, K.C. (1976). Unique contributions of churches and clergy to community health. Community Mental Health Journal, 12 (1), 20-28.

Maton, K.I. \& Rappaport, J. (1984). Empowerment in a religious setting: A multivariate investigation. Prevention in Human Services, 3, 37-72.

Moos, R.H. (1987). The social climate scales: $A$ users guide. California: Consulting Psychologists Press.

Murrel, S.A. (1973). Community psychology and social systems. New York: Behavioral publications.

Myers, J.K., Lindenthal, J.J. \& Pepper, M.P. (1975). Life events, social integration and psychiatric symptomatology. Journal of Health and Social Behaviour, 16, 421-427.

Pargament, K.I. (1982). The interface among religion, religious support systems, and mental health. In D.E. Biegel \& A.J. Naparstek (Eds), Community support systems and mental health. New York, Springer Publishing.

Pargament, K.I., Silverman, W., Johnson, S., Echemendia, R. \& Snyder, S. (1983). The psycho-social climate of religious congregations. Americal Journal of Community Psychology, 11(4), 351-381.

Pargament, K.I., Tyler, F.B. \& Steele, R.E. (1979). The church/synagogue and the psycho-social competence of the member: An initial inquiry into a neglected dimension. American Journal of Community Psychology, 2(6), 649-664.

Petersen, A.C. \& Kellam, S.G. (1977). Measurement of the psychological well-being of adolescents: The psychometric properties and assessment procedures of the How I Feel. Journal of Youth and Adolescence, 6, 229-247.

Rabkin, J.G. \& Struening, E.L. (1976). Life events, stress and 
illness. Science, 194, 1013-1020.

Rappaport, J. (1981). In praise of paradox: A social policy of empowerment over prevention. American Journal of Community Psychology, 9(1), 1-25.

Reif, R. (1968). Social intervention and the problem of psychological analysis. American Psychologist, 22,
524-530.

Robinson, J.P. \& Shaver, P.R. (1976). Measures of social psychological attitudes. Michigan: University of Michigan.

Turner, R.J. (1981). Social support as a contingency in psychological well-being. Journal of Health and Social Behavior, 22, 357-367. 